\title{
Analysis of static equilibrium in unilateral transfemoral amputation: a case report
}

\author{
Vaneska de Fátima Amorim Silva', Flávia Regina Ferreira Alves', Cíntia Aline Martins', Helen Cristina Monteiro', \\ Danillo Barbosa², Monica Beatriz Ferreira', Bruno Bonfim Foresti²
}

\begin{abstract}
Background: In subjects with transfemoral amputation, mechanical changes are observed due to the dependence of an artificial limb for the support of body weight associated with a loss of musculature of the lower limb, leading to compensatory movements in the hip, pelvis and trunk during gait. Objective: This study aimed to analyze two models of prosthetic feet, articulated and solid ankle cushion hell (SACH), in relation to static balance. Methodology: This is an observational and interventional case study, with a quanti-qualitative character of a transfemoral amputee. The adapted Romberg test and the evaluation with the baropometer were used. This study was approved by the research ethics committee of the South Minas Foundation's teaching and research foundation - FEPESMIG and approved according to the number of protocol 1,826,838 and CAAE 61766416.9.0000.5111. Results: Data from the evaluation of baropodometry associated with the Romberg test for the articulated foot showed a pressure of $\pm 50.0 \%$, anterior quadrant pressure of $20 \%$, posterior quadrant pressure of $\pm 30.0 \%$, a posterior quadrant distribution of $\pm 60.0 \%$ and an anterior quadrant distribution of $\pm 40.0 \%$. On the other hand, the $\mathrm{SACH}$ foot data showed a pressure of $50 \%$, anterior quadrant pressure of $\pm 20.0 \%$, posterior quadrant pressure of $\pm 30.0 \%$, a posterior quadrant distribution of $\pm 60.0 \%$, and anterior quadrant distribution of $\pm 40.0 \%$. Conclusion: The choice of foot type should take into account the individuality of the patient, as well as the application of a complete program of intervention in physiotherapy.
\end{abstract}

Keywords: Amputation; Rehabilitation; Prosthesis; Physiotherapy.

\section{INTRODUCTION}

In subjects with transfemoral amputation, mechanical changes are observed due to the dependence of an artificial limb for the support of body weight associated with a loss of musculature of the lower limb, leading to compensatory movements in the hip, pelvis and trunk during gait ${ }^{(1)}$. The prostheses are developed to provide better comfort to the limb amputated according to the anatomy and physiology of the subject, providing an improvement in postural control, orthostatism and ambulation ${ }^{(2)}$. Amputee walking may differ due to prosthetic foot, lack of active dorsiflexion, plantar flexion, strength, power, and proprioception, resulting in biomechanical alterations ${ }^{(3)}$. There are basically four types of feet, known as Solid Ankle-Cushion Heel (SACH) foot, dynamic, articulated and dynamic response ${ }^{(4)}$. Postural control involves two strands: the static balance in which it consists of the ability to exercise activities and keep the body in balance in rest situations and the dynamic balance that fits into the ability to exercise activities and keep the body in balance in situations of movement, when submitted to various stimuli(5). The proprioceptive, vestibular and visual systems give rise to neurological impulses, whose information is processed by the central nervous system and return through the efferent pathways to maintain balance control ${ }^{(6)}$. The importance of these systems in an amputation occurs in the involvement of the structures involved in the stages of sensory information processing, such as damage to the mechanoreceptors, located in the stump and can alter the balance ${ }^{(7)}$.

The equilibrium can be analyzed by balancing platforms, among which the baropodometer evaluation, which analyzes the weight discharge quantifying the body oscillations, being able to verify if the displacement of the pressure center as the mobile point of the feet that oscillate with the transfer of weight ${ }^{(4-6)}$. The present study aimed to analyze the static balance of an subject submitted to transfemoral amputation, using 2 models of prosthetic foot, being evaluated by specific instruments after physiotherapeutic intervention.

Corresponding Author: Prof Dr Danillo Barbosa. Address: Rua Lamartine Silva Paiva 960. Condomínio Vilas do Atlântico, apartamento 102. Bairro Jardim Olímpico, Pouso Alegre (MG), Brasil. Cep: 37550-000. Phone 005535 984276895. E-mail: danillo.barbosa@hotmail.com

2 Universidade Estadual do Centro Oeste - Unicentro - Guarapuava (PR), Brasil

Full list of author information is available at the end of the article.

Financial Support: nothing to declare

Submission date 03 September 2018; Acceptance date 16 October 2018; Publication date 7 November 2018 


\section{STUDY DESIGN}

\section{Ethical Aspects}

The present study was submitted to the Ethics in Research Committee of the South Minas Research and Education Foundation - FEPESMIG and approved according to the protocol number 1.826.838 and CAAE 61766416.9.0000.5111. As established by the ethics and research committee with human beings, the participant received all the guarantees regarding his participation in the study, as well as, if in case of any inconvenience during the study, the patient could leave the study without any physical or moral damages, psychological and financial. After receiving all the information pertinent to the study, the patient received a copy of the informed consent form, which was read, signed and delivered by the patient. This was an observational and interventional case study, with a quali-quantitative character. Data collection occurred between June and July 2017 at the reference center in physical medicine and rehabilitation of a state of Minas Gerais.

\section{Characteristics of the Case Report}

The present study deals with a case description of a patient of 25 years, $88 \mathrm{~kg}, 1.75 \mathrm{~m}$. The patient in question was the victim of a truck accident, which caused serious injuries to the lower limbs, especially in the lower left limb, which due to complications after the accident was amputated at the transfemoral level. After the surgery, the patient was hospitalized for 3 days after discharge and remained in his home for 30 days, and only sought a physical therapy service 55 days after the postoperative period. In the physiotherapy sector the patient was evaluated, and the short, medium and long term goals were established by the rehabilitation team.

\section{Baropodometry Evaluation}

The static balance was measured through the plantar pressure center using baropodometry ${ }^{(8-10)}$ associated with the adapted Romberg test ${ }^{(11,12)}$. Baropodometry is an objective and quantitative exam that analyzes plantar pressure on a platform composed of sensors that aim to measure and compare the pressures developed at different points of the plantar region in several different situations. This means of evaluation has no empirical scores, but rather reliable and objectively measured data. The use of baropodometry in the evaluation of the body posture balance is a very recent technology, there is very little research relating to its use, most of the time it is used for clinical purposes, which explains to some extent, few academic articles published in this area ${ }^{(8-10)}$.

\section{Romberg Test}

When examining the Romberg's signal, the examiner observes the patient's postural balance on a flat surface, standing initially with his feet together and with his eyes open, and then examining him in the same position with his eyes closed $^{(11,12)}$. On the days of collection the subject climbed the baropodometer and was instructed to remain with arms at the side of the body and with open eyes fixed at an imaginary point on the wall and then with eyes closed, remaining in that position for 30 seconds. The choice of the Romberg test adapted for the evaluation of the static balance in 30 seconds is justified by the results obtained, which demonstrated that the largest oscillations occur in the interval of 30 seconds ${ }^{(11,12)}$. During collection, the individual was subject to minimal risk and may present slight discomfort during collection.

\section{Intervention Protocol}

The physiotherapeutic protocol(13) consisted of 15 physiotherapeutic care in the sector of the physical rehabilitation center, with a frequency of 3 times a week, with a duration of 60 minutes of care. The first care was preceded by a detailed postural evaluation of the patient. Still during the evaluation, the patient had the first contact with the prosthesis, as he was aware, that he would have 2 options of foot prosthesis to use, and that the one that achieved the best results in terms of static and dynamic equilibrium would be the prosthesis. The suggested prosthetic foot models were: SACH foot and the articulated foot. Physiotherapeutic interventions were composed of sensory-motor exercises of double task and gait with obstacles. All interventions were divided into 30 minutes with articulated prosthetic foot and 30 minutes with solid prosthetic foot ankle cushion hell (SACH). The protocol was divided into 5 phases:

- Phase I: balance with bipodal support, associated with double task of adduction and abduction of shoulder with mechanical resistance of $2 \mathrm{~kg}$, number of repetitions 3 times, with interval of 30 seconds between sets;

- Phase II: performance of the balance board with bipodal support, associated with double task of flexion of shoulder with mechanical resistance with theraband average resistance, number of repetitions 3 times, with interval of 30 seconds between the series;

- Phase III: jump, bipodal, on the trampoline, associated with double task of jumping and throwing a medicine ball of $1 \mathrm{~kg}$, number of repetitions 3 times, with interval of 30 seconds between sets;

- Phase IV: performance of gait training with resistance of a $1 \mathrm{~kg}$ bilateral shin guard, number of repetitions 3 times, with interval of 30 seconds between sets;

- Phase V: performing the training of walking changing the direction and passing through obstacles stuck in the ground, with average distance of $30 \mathrm{~cm}$, number of repetitions 3 times, with interval of 30 seconds between the series; 
For the processing of data captured in the platform of baropodometry was used the program Microsoft Excel, for tabulation of the data. The results were described in descriptive form and described in percentage.

\section{RESULTS}

The measurement of the plantar pressure center through the baropodometry platform associated with the Romberg test, at this first moment was applied to the articulated foot. Foot pressure was very close to the ideal in the evaluation, with $\pm 51.0 \%$ pressure discharge in the prosthetic foot (left) and $\pm 49.0 \%$ in the right foot (Table 1 ).

The data obtained in the evaluations with the foot $\mathrm{SACH}$ one perceives that the pressure was ideal in the 1st reassessment and $\pm 50 \%$ of pressure discharge in the left foot, which is the lower limb amputated and right foot, at the end of the protocol (final evaluation) was presented $\pm 45 \%$ of left foot pressure and $\pm 55 \%$ of right foot. The pressure of the left quadrant of the left foot with the eyes opened evolved from the evaluation that presented $\pm 23 \%$, in the final evaluation already presented $\pm 27 \%$. (Table 2 ).

The comparative data of baropodometry of the articulated prosthetic foot (Figs. A, B and C) and SACH foot (Figs. D, E and F) associated to the modified Romberg's test with open eyes were described in figure 1 . The evaluation was performed in 3 different moments, being pre intervention, in the 7th physiotherapeutic intervention and after the 15th intervention. It can be observed that the plantar distribution in Figures D, E and F referring to the SACH foot have a greater filling in the platform, corresponding to a better adaptation to the baropodometry test, and consequently providing a greater static balance with the eyes closed to the patient.

Table 1. Baropodometry of the articulated Foot.

\begin{tabular}{|c|c|c|c|c|c|c|c|}
\hline \multirow{2}{*}{\multicolumn{2}{|c|}{$\frac{\text { DATE }}{\text { Eys open-closed }}$}} & \multicolumn{2}{|c|}{ Evaluation } & \multicolumn{2}{|c|}{ 19 Reavaluation } & \multicolumn{2}{|c|}{ Final Evaluation } \\
\hline & & $\mathrm{OE}$ & CE & $\mathrm{OE}$ & CE & $\mathrm{OE}$ & CE \\
\hline \multirow{5}{*}{$\begin{array}{l}\text { Left } \\
\text { Foot }\end{array}$} & Pressure & $51 \%$ & $41 \%$ & $55 \%$ & $51 \%$ & $46 \%$ & $42 \%$ \\
\hline & Posterior Quadrant Pressure & $17 \%$ & $12 \%$ & $19 \%$ & $11 \%$ & $27 \%$ & $23 \%$ \\
\hline & Anterior Quadrant Pressure & $33 \%$ & $29 \%$ & $36 \%$ & $39 \%$ & $19 \%$ & $19 \%$ \\
\hline & Posterior Quadrant Distribution & $34 \%$ & $30 \%$ & $35 \%$ & $22 \%$ & $59 \%$ & $55 \%$ \\
\hline & Anterior Quadrant Distribution & $66 \%$ & $70 \%$ & $65 \%$ & $78 \%$ & $41 \%$ & $45 \%$ \\
\hline \multirow{5}{*}{$\begin{array}{l}\text { Left } \\
\text { Rigth }\end{array}$} & Pressure & $49 \%$ & $59 \%$ & $45 \%$ & $49 \%$ & $54 \%$ & $58 \%$ \\
\hline & Posterior Quadrant Pressure & $32 \%$ & $40 \%$ & $33 \%$ & $28 \%$ & $30 \%$ & $36 \%$ \\
\hline & Anterior Quadrant Pressure & $17 \%$ & $18 \%$ & $12 \%$ & $22 \%$ & $24 \%$ & $22 \%$ \\
\hline & Posterior Quadrant Distribution & $65 \%$ & $69 \%$ & $73 \%$ & $56 \%$ & $56 \%$ & $63 \%$ \\
\hline & Anterior Quadrant Distribution & $35 \%$ & $31 \%$ & $27 \%$ & $44 \%$ & $44 \%$ & $37 \%$ \\
\hline
\end{tabular}

Note: $\mathrm{OE}=$ open eyes; $\mathrm{CE}=$ closed eyes. References - Pressure $= \pm 50.0 \%$. Anterior Quadrant Pressure $=20 \%$ Posterior Quadrant Pressure $= \pm 30.0 \%$. Posterior Quadrant Distribution $=65- \pm 60.0 \%$. Anterior Quadrant Distribution $= \pm 35.0- \pm 40.0 \%$.

Table 2. Baropodometry of Solid Ankle-Cushion Heel Foot.

\begin{tabular}{|c|c|c|c|c|c|c|c|}
\hline \multirow{2}{*}{\multicolumn{2}{|c|}{$\frac{\text { DATE }}{\text { Eyes open-closed }}$}} & \multicolumn{2}{|c|}{ Evaluation } & \multicolumn{2}{|c|}{ 19 Reavaluation } & \multicolumn{2}{|c|}{ Final Evaluation } \\
\hline & & OE & CE & OE & CE & OE & CE \\
\hline \multirow{5}{*}{$\begin{array}{l}\text { Left } \\
\text { Foot }\end{array}$} & Pressure & $54 \%$ & $46 \%$ & $55 \%$ & $50 \%$ & $48 \%$ & $45 \%$ \\
\hline & Posterior Quadrant Pressure & $23 \%$ & $11 \%$ & $22 \%$ & $15 \%$ & $27 \%$ & $35 \%$ \\
\hline & Anterior Quadrant Pressure & $32 \%$ & $35 \%$ & $33 \%$ & $35 \%$ & $20 \%$ & $24 \%$ \\
\hline & Posterior Quadrant Distribution & $42 \%$ & $24 \%$ & $40 \%$ & $30 \%$ & $57 \%$ & $76 \%$ \\
\hline & Anterior Quadrant Distribution & $58 \%$ & $76 \%$ & $60 \%$ & $70 \%$ & $43 \%$ & $24 \%$ \\
\hline \multirow{5}{*}{$\begin{array}{l}\text { Left } \\
\text { Rigth }\end{array}$} & Pressão & $46 \%$ & $54 \%$ & $45 \%$ & $50 \%$ & $52 \%$ & $55 \%$ \\
\hline & Posterior Quadrant Pressure & $35 \%$ & $31 \%$ & $31 \%$ & $33 \%$ & $29 \%$ & $36 \%$ \\
\hline & Anterior Quadrant Pressure & $11 \%$ & $23 \%$ & $14 \%$ & $17 \%$ & $23 \%$ & $19 \%$ \\
\hline & Posterior Quadrant Distribution & $76 \%$ & $58 \%$ & $69 \%$ & $66 \%$ & $55 \%$ & $65 \%$ \\
\hline & Anterior Quadrant Distribution & $24 \%$ & $42 \%$ & $31 \%$ & $34 \%$ & $45 \%$ & $35 \%$ \\
\hline
\end{tabular}

Note: $\mathrm{OE}=$ open eyes; $\mathrm{CE}=$ closed eyes. References - Pressure $=50 \%$. Anterior Quadrant Pressure $= \pm 20.0 \%$ Posterior Quadrant Pressure $= \pm 30.0 \%$. Posterior Quadrant Distribution $=65- \pm 60.0 \%$. Anterior Quadrant Distribution $= \pm 35.0- \pm 40.0 \%$. 

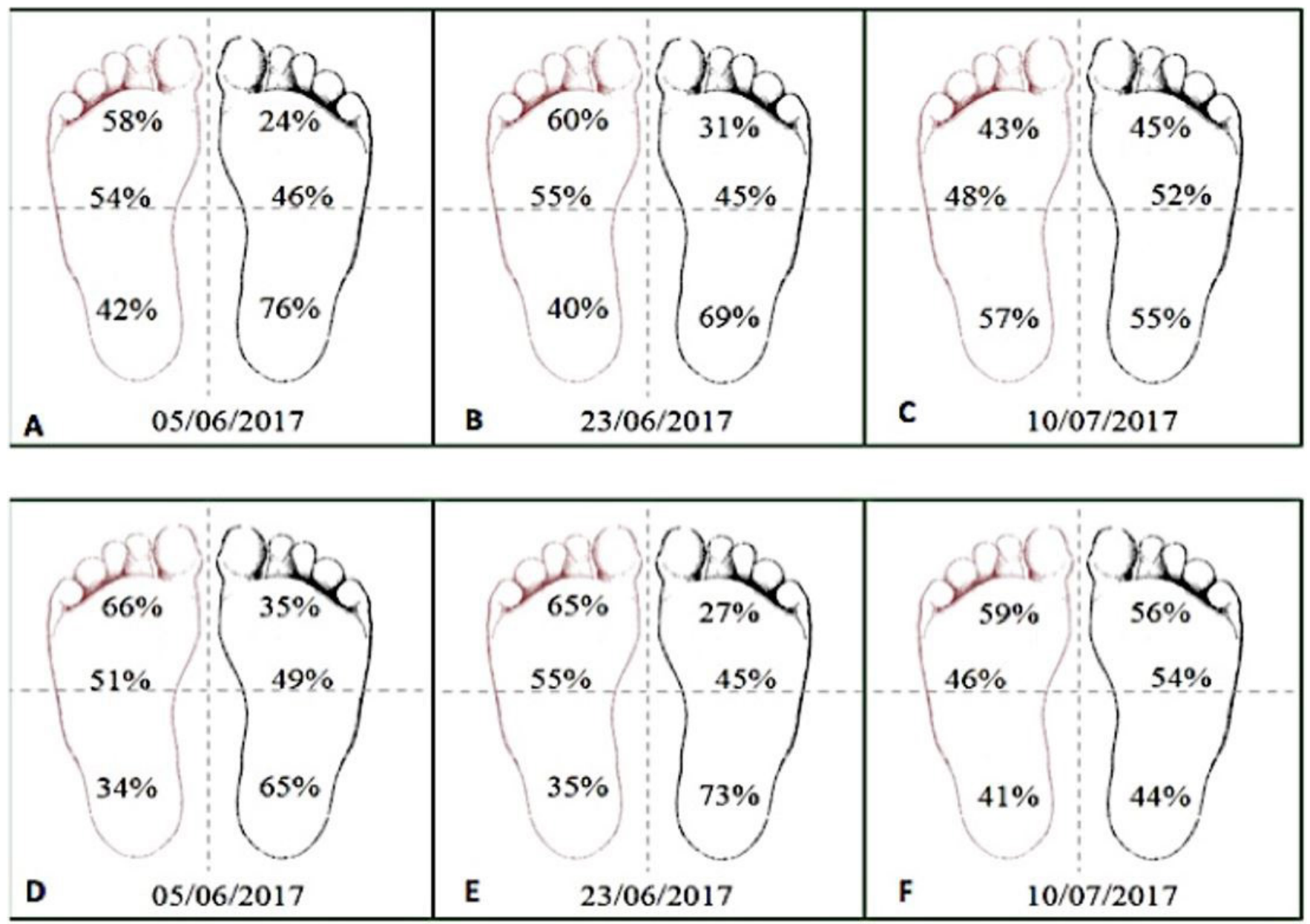

Figure 1. Evaluation with baropodometry associated with the modified Romberg test with open eyes.

Note: Figure A, B and C referring to the baropodometry test of the articulated prosthetic foot associated with the modified Romberg Test with open eyes. Figure D, E and F referring to the SACH foot baropodometry test associated with the open-eyes modified Romberg's test.

The comparative data of the articulated prosthetic foot baropodometry (Figs. $\mathrm{H}, \mathrm{H}$ and $\mathrm{I}$ ) and $\mathrm{SACH}$ foot (Figs. J, K and L) associated with the modified Romberg's closed-eyes test were described in figure 2 . The evaluation was performed in 3 different moments, being pre intervention, in the 7th physiotherapeutic intervention and after the 15th intervention. Note that in the 1st pre-intervention evaluation the patient presented better static balance as well as greater foot filling on the platform using the articulated foot, in the evaluation performed in the 7th intervention the articulated foot also presented a superior result and after the 15th intervention the evaluation indicated superior advantage of the SACH foot, regarding the balance associated with the Romberg test with the eyes closed.

\section{DISCUSSION}

Amputees need a longer time to respond appropriately to situations of disturbance to balance, since they present alterations in the somatosensory system, important for maintaining balance ${ }^{(14)}$. Some parameters of pressure center distribution (COP) are accepted as normal, for example, with respect to the load, or pressure distribution in the anteroposterior direction should have an approximate behavior of: $40 \%$ in the anterior portion and $60 \%$ in the posterior; turn in the lateral-lateral direction this load distribution to be around $50 \%$ in each support. Alterations in this proportion of load distribution are common and can have the most diverse causes: anthropometric, muscular, articular, postural, proprioceptive ${ }^{(15)}$. The proprioceptive, vestibular and visual systems give rise to neurological impulses, whose information is processed by the central nervous system and return through the afferent pathways to maintain balance control ${ }^{(16)}$. Postural control can also be influenced by several physiological factors, such as breathing, heart rate and venous return, which generate constant oscillations in the body balance that can be verified through the displacement of the pressure center ${ }^{(17)}$. In a study of Fritzen ${ }^{(18)}$ that analyzed the gait kinematics of 11 transtibial amputees with different types of prosthetic feet, he presented that the articulated foot, compared to the other 

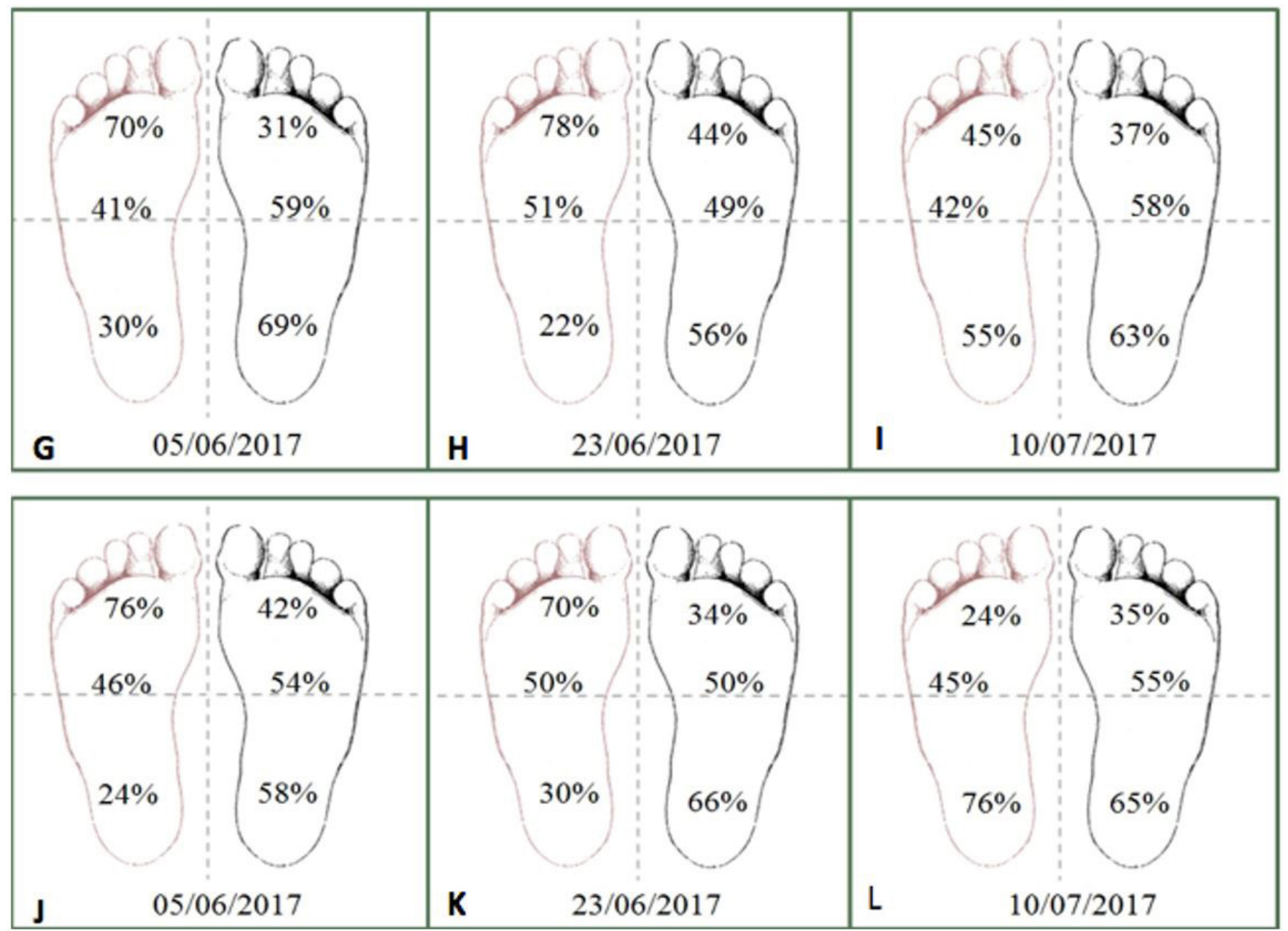

Figure 2. Baropodometry evaluation associated with the modified Romberg test with closed eyes.

Note: Figure G, H and I referring to the baropodometry test of the articulated prosthetic foot associated to the modified Romberg test with closed eyes. Figure J, K and L for the SOP foot baropodometry test associated with the closed-closed modified Romberg's test

feet, showed a greater movement of plantar and dorsal flexion, without the accumulation and return of energy, influencing the increased knee and hip flexion. These results point to the benefits of sensory-motor intervention in reducing plantar contact pressure in subjects with transfemoral amputation. However, the subject did not have alterations regarding the asymmetry of plantar pressure between the right and left feet after the intervention, leading to in consideration also the presence or not of the vision.

The time of use of the prosthesis is also directly related to the oscillations, because the longer the use time, the more imbalance tends to decrease ${ }^{(19)}$. In general, the subject presented improvement in the pressure distribution between the feet, being presented both in bipodal support with open eyes and bipodal with closed eyes, both articulated foot and $\mathrm{SACH}$ foot, but a greater pressure was identified in the right support of this subject. This may be related to the intervention time. Even though there is no similarity in the values of the pressure distribution between the feet, the decrease in plantar pressure promoted by sensory-motor exercise can improve the somatosensory afferents of the feet, contributing to the facilitation of postural control and, consequently, to decrease the risk of falls. During the analysis on the baropodometry platform, the subjects were placed in orthostatic position for 30 seconds on the pressure platform, looking at an imaginary fixed point located on the wall. This time for data collection of baropodometric variables was the same as that adopted in another study ${ }^{(20)}$. When studying the oscillations in the sagittal plane and in the frontal plane in amputated and non-amputated individuals, they noticed that the largest oscillations of the body occur within this time interval. In a study of Barauna ${ }^{(20)}$ performed using biophotogrammetry, they demonstrated that transtibial amputees obtained a significant anterior oscillation in $\mathrm{cm}$ when compared to control subjects without amputation, which is consistent with the findings of another study ${ }^{(21)}$ that compared the static and dynamic balance of limb amputees inferior and verified that a greater oscillation is a consequence of the change of the center of pressure in 
the anteroposterior plane, also reporting that the instability was related to this oscillation. Factors such as fear of falling, as well as difficulty in unloading body weight symmetrically could also contribute to the increase of these oscillations and consequent decrease of the stability mechanism. All the amputees analyzed did not present the articulated ankle, and the foot was SACH type.

\section{CONCLUSION}

The present study noted that the articulated foot presents greater functional mobility, that is, it would be better used in individuals with greater gait potential, and however, the $\mathrm{SACH}$ foot presents greater safety, stability and greater area ofcontact with soil. Therefore, it is concluded that the choice of foot type should take into account the individuality of the patient, as well as the application of a complete program of intervention in physiotherapy.

\section{AUTHOR'S CONTRIBUTIONS}

VFAS initiated the research project, submitted to the ethics committee and monitored the data collection; FRFA reviewed the statistics and the English text, CAM participated in the data collection and writing of the text in Portuguese; HCM participated in data collection and was responsible for patient follow-up during the study; DB participated in the static analysis and revision of the English text; MBF revised the text in Portuguese; BBF reviewed the texts in Portuguese and English.

\section{CONFLICT OF INTEREST}

The authors declare that they have no competing interests.

\section{AUTHORS DETAILS}

${ }^{1}$ Centro Universitário do Sul de Minas - UNIS-MG - Varginha (MG), Brasil

\section{REFERENCES}

1. Devan H, Carman A, Hendrick P, Hale L, Ribeiro DC. Spinal, pelvic, and hip movement asymmetries in people with lower-limb amputation: Systematic review. Journal of rehabilitation research and development. 2015; 52: 1-12.

2. Viegas JAL. Estudo Biomecânico na Marcha de Indivíduos Amputados do Membro Inferior. Tese de Doutorado. Universidade do Porto. 2017, 55-9.

3. Chamlian TR, Angrisani PG, Resende JM, Celestino ML, Say KG, Barela AMF Avaliação do padrão postural e marcha de pacientes amputados vasculares transtibiais protetizados. Acta Fisiátrica. 2013; 20: 207-212.

4. Fritzen LFS. Análise Cinemática da marcha de amputados transtibiais com diferentes tipos de pés protéticos. (Mestrado). Programa de pósgraduação em Bioengenharia, Universidade do Vale da Paraíba, São José dos Campos. 2012, 43-9.
5. Teixeira CS, Lemos LFC, Lopes LFD, Mota CB A influência dos sistemas sensoriais na plataforma de força: estudo do equilíbrio corporal em idosas com e sem queixa de tontura. Revista CEFAC. 2010; 12: 1-15.

6. Ribeiro MP. Avaliação da estabilidade estática em indivíduos com amputação transtibial unilateral de origem traumática. Trabalho de Conclusão de Curso (Graduação em Fisioterapia) - Universidade Federal de Juiz de Fora, Juiz de Fora, 2010, 44-9.

7. Hall CM; Brody LT. Exercício terapêutico: na busca da função. Rio de Janeiro: Guanabara Koogan, 2001.

8. Moreira M, Moreira N. Comparação das estratégias posturais pelo exame baropodométrico. Revista Terapia Manual. 2003; 2: 28-32,

9. Marczak J. Análise postural através de baropodometria no ballet clássico. Monografia - Centro Universitário de Maringá. Maringá-PR, 2004; 15-33.

10. Schmidt A; Bankoff ADP; Zamai CA; Barros DD. Estabilometria: Estudo do equilíbrio postural através da baropodometria eletrônica. In: Congresso Brasileiro de Ciências Do Esporte. Anais. 2003; 47-51.

11. Maranhão-Filho PA, Maranhão ET, Silva MM, Lima MA. Rethinking the neurological examination I: static balance assessment. Arq NeuroPsiquiatr. 2011; 69: 954-8.

12. Baraúna MA. Estudo comparativo entre a avaliação do equilíbrio estático de indivíduos amputados e não amputados (Tese Doutorado em Motricidade Humana). Universidade Técnica de Lisboa, Lisboa (Portugal), 1997, 20-8.

13. Longato MW, Castro PR, Keller KCR, Romanovitch D. Efeito do isostretching no equilíbrio de indivíduos amputados: um estudo de caso. Fisioterapia em Movimento. 2011; 24: 689-696.

14. Novak VC. Análise da distribuição da pressão plantar e do equilíbrio em indivíduos com amputações unilaterais por meio de parâmetros baropodométricos e estabilométricos. (Dissertação) Instituto de Pesquisa e Desenvolvimento da Universidade do Vale do Paraíba. São José dos Campos. 2010, 33-9.

15. Norkin CC, Levangie PK. Articulações, estrutura e função: uma abordagem prática e abrangente. São Paulo: Revinter; 2001.

16. Ribeiro MP. Avaliação da estabilidade estática em indivíduos com amputação transtibial unilateral de origem traumática. Trabalho de Conclusão de Curso (Graduação em Fisioterapia) - Universidade Federal de Juiz de Fora, Juiz de Fora. 2010; 24-36.

17. Schmidt A, Bankoff ADP, Zamai CA, Barros DD. Estudo do equilíbrio postural através da baropodometria eletrônica. Congresso Brasileito De Ciências Do Esporte. 2003 Octuber p19-33.

18. Fritzen LFS. Análise Cinemática da marcha de amputados transtibiais com diferentes tipos de pés protéticos. (Mestrado). Programa de Pósgraduação em Bioengenharia, Universidade do Vale da Paraíba, São José dos Campos. 2012; 20-9.

19. Longato MW, Castro PR, Keller KCR, Romanovitch DI. Efeito do isostretching no equilíbrio de indivíduos amputados: um estudo de caso. Fisioterapia em Movimento. 2011; 24: 689-696.

20. Baraúna MA. Estudo do equilíbrio estático de idosos e sua correlação com quedas. Revista Fisioterapia Brasil. 2006; 4: 136-41.

21. Buckey JG, O’Driscoll D, Benett SJ. Postural sway and active balance performance in highly active lower-limb amputees. American Journal of Physical Medicine and Rehabilitation. 2002; 81: 13-20. 